\title{
Boom in Canada-China research collaborations
}

\section{Published at www.cmaj.ca on Nov.18}

$\mathrm{I}$ n the winter of 1938, Dr. Henry Norman Bethune left Canada and arrived in China's Shanxi province during the Second Sino-Japanese War. Virtually unknown in his home country, he worked with Mao Zedong's Communist Party performing emergency battlefield surgeries, set up blood transfusion stations and created a training program for doctors, nurses and orderlies.

Most knew Bethune by his Chinese name, Bai Qiu En, a man who became a national hero after dying in 1939 of blood poisoning. Mao Zedong was so inspired by Bethune's acts that he wrote an essay, "In Memory of Norman Bethune," that, years later, children still memorize and recite. A medical school and a hospital were nammed in Bethune's memory.

Thousands of Canadian medical professionals and researchers have followed in Bethune's footsteps, travelling to China to work on a variety of research projects and exchanges.

It's a practice that is booming, and almost weekly, it seems, there are announcements from Canadian governments or universities about new collaborative projects with China.

"There is tremendous opportunity for research between Canada and China," says Dr. Massey Beveridge, who founded the Office of International Surgery at the University of Toronto in Ontario and now practises in northern Newfoundland.

Beveridge first ventured to China in 1987, as a 26-year-old medical student from Queen's University in Kingston, Ontario, to become part of a group of 50 foreign students from more than 25 different countries doing medical work at Rui Jin Hospital in Shanghai. "They were tremendously welcoming to a little junior Canadian medical student," he says. "It was a great learning experience."

So great, in fact, that Beveridge

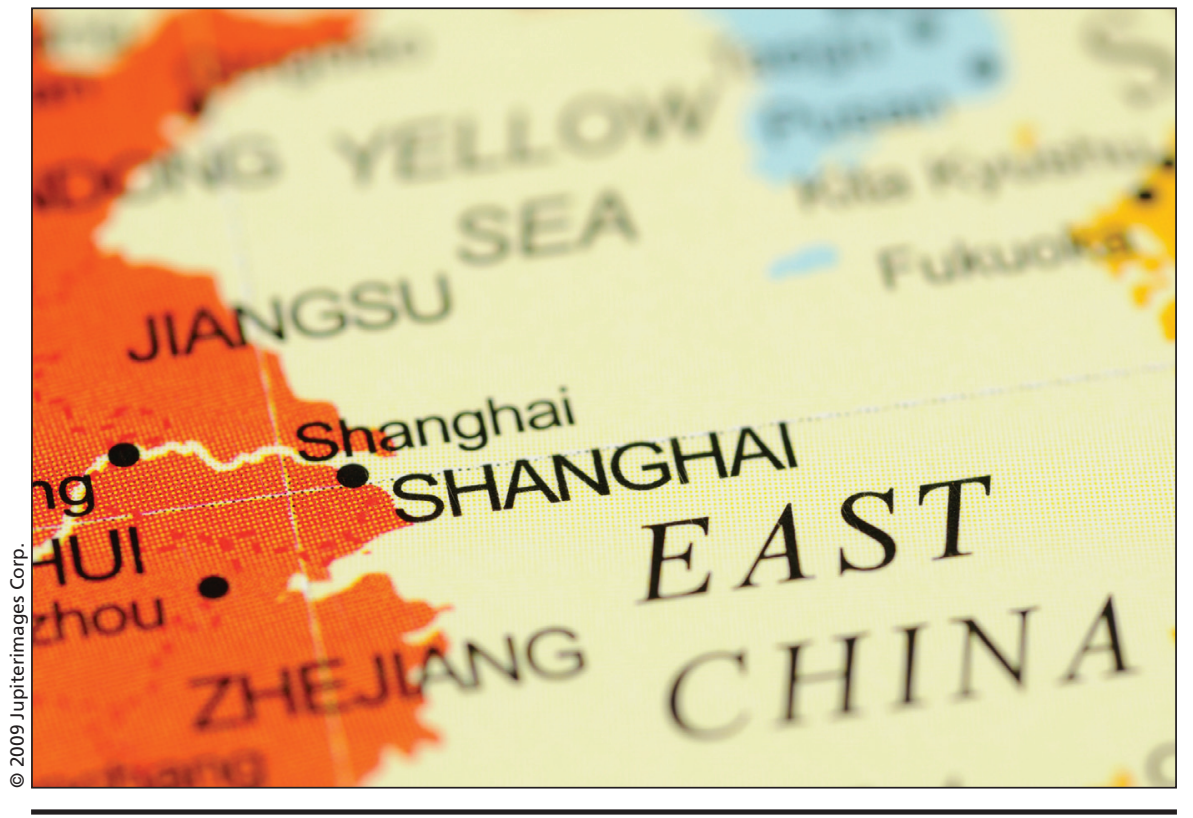

Thousands of Canadian medical professionals and researchers have travelled to China to work on a variety of research projects and exchanges.

returned 17 years later to help set up a collaborative program between the Rui Jin Hospital Burn Unit and the Ross Tilley Burn Centre in Toronto.

As China continues to evolve into one of the world's major scientific players, such projects will only continue to multiply, predicts Dr. Alain Beaudet, president of the Canadian Institutes of Health Research, which has inked four separate research agreements with the government of China and plans to significantly expand that portfolio in the future.

China is "investing massively in science and technology," Beaudet says. "I just got back from my third trip to China and every time, there are new research centres that have sprung up like mushrooms. It's amazing. They're tremendously effective at bringing the diaspora back and attracting graduate students. They're bringing back full professors from the best universities in the States and they give them, basically, research institutes."

In its efforts to elevate the nation's scientific enterprise, China's invest- ment in research (an average annual increase of $18 \%$ between 1995 and 2006) includes a strategy to increase collaboration with top Western scientists, Beaudet adds. For example, he cites recent negotiations on expanding an existing $\$ 300000$, three-year agreement with the Natural Sciences Foundation of China, which now funds 20 projects across the spectrum of biomedical research. "And they don't want to just fund more people. They want to fund them at a higher level, so that they'll attract even better scientists, which I think is telling."

A wide variety of research programs now link the two countries, including one sponsored by the International Development Research Centre and the Canadian Research Chairs Program, which brought Shao Yiming, chief scientist at China's National Centre for AIDS/STD Control and Prevention, together with Wu Jianhong, a mathematician at York University in Toronto. The plan is to train and establish a team (involving more than 20 Chinese graduate and postdoctoral 
students) to model outbreaks of HIV/AIDS, tuberculosis and hepatitis in China.

Jianhong says the work has significant benefits for both Canada and China. "Whatever happens in China has a tremendous impact for Canada, in both public health and economics," he says. "China has a huge population and the strength of the system will provide a large amount of public health data which is extremely valuable for the global control of disease as well as for the interest of Canadian health."

It should also help China with its plan to reform its health care system. Beaudet says the Chinese government has expressed a particular interest in health services research, largely because the Canadian health care system is seen as a model which might help China in its bid to reform its system by 2020 to provide "safe, effective, convenient and affordable" health services to all its citizens (CMAJ 2009. DOI:10.1503/cmaj .090926).

Beaudet also notes that China presents unique opportunities for clinical research, because its enormous population makes it easier to recruit subjects, as well as opportunities for research that bridges Western and traditional Chinese medicine. For example, there's considerable Canadian interest in the use of Chinese herbal medicine as a treatment for drug addiction, while there's considerable Chinese interest in determining the therapeutic efficacy of various herbal compounds, he says. "Then the real challenge, if it is effective, is determining what are the active ingredients, isolating them and patenting them. There's potential here certainly for the discovery of new and interesting drugs."

Further evidence of China's efforts to rejuvenate its scientific enterprise can be found in university enrolments and the number of scientific articles published by its researchers. The Chinese Ministry of Education says there has been a fivefold increase in the number of students in universities, to 25 million, and a fourfold increase in the number of scientific papers published between 1998 and 2008, from 20000 to 112 000. By 2006, China had moved past Canada, France, Russia, Japan, the UK and Germany to take second place, behind the US, in papers published internationally.

The ministry statistics also indicate that there has been tremendous growth in papers published in the areas of immunology, microbiology, molecular biology and genetics. For example, there were 500 papers published in immunology between 1999 and 2003, and 2100 between 2004 and 2009.

Ministry numbers also indicate a significant increase in the number of papers coauthored with scientists from other countries. Roughly $9 \%$ of such coauthored papers involved scientists from the United States and 1.7\% (about 7500) involved collaborations with Canadians.

Despite the increase in collaboration between Canada and China, there are still challenges to overcome. Beaudet notes that there's still a need for China to further develop the notion of peer review. "It's not something that's still very ingrained in the culture," he notes, but adds that China is rapidly improving on that score.

Beveridge says Canadians also have to avoid the tendency to assume that their approach is the right one. "It's an exchange of information," he says. "Not just going there and telling them: 'Well, this is how you do it'."

It's also important to allow the host country to decide what research is needed within the context of its national health care system, Beveridge says. "You need to match skill with demonstrated need. You have to let the people on the ground determine the need and see what we have to help meet that need. And whether it's a need for surgical techniques, or ICU strategies or research techniques, they're all important."

"They have very good doctors and some very big challenges," Beveridge adds. "And they're trying to deal with them."

Jianhong forecasts that the drive to promote international collaboration will only intensify. "With China's increasing economic power, its research will also increase. We have highly trained people," he says. "The future will be bigger, with increased cutting edge research." - Katie Lewis, Beijing, China, and Wayne Kondro, CMAJ

DOII:10.1503/cmaj.109-3106 